\title{
Bile Acid-Induced Increase in Bile Acid-Independent Flow and Plasma Membrane NaK-ATPase Activity in Rat Liver
}

\author{
F-J. Wannagat, R. D. Adler, and R. K. Ockner, Department of Medicine and Liver \\ Center, University of California, School of Medicine, San Francisco, \\ California 94143
}

A B S T RACT Previous studies showed that in rats with obstruction of the bile ducts draining the median and left hepatic lobes, and in rats with normal bile ducts in which the bile acid pool size and secretion were augmented by 48 -h intraduodenal infusion of taurocholate, bile acid flux through secreting hepatocytes was increased. Under these conditions, taurocholate transport maximum exhibited a time-dependent adaptation to increased secretory load.

Unexpectedly, bile acid-independent canalicular flow in these experimental models also was found to be increased when measured at $48 \mathrm{~h}$. Relative to controls, bile acid-independent flow per gram of nonobstructed liver was increased approximately threefold in selectively obstructed rats and $43 \%$ in bile acid-loaded rats with normal ducts. In rats infused with bile acids at similar rates for only $16 \mathrm{~h}$, no increase was observed. Studies with $\left[{ }^{14} \mathrm{C}\right]$ erythritol suggested that the increased bile flow under these conditions was of canalicular origin.

NaK-ATPase activity in canaliculi-enriched liver plasma membrane preparations from the nonobstructed lobes of selectively obstructed rats and from 48-h bile acid-loaded rats was increased by $47 \%$ and $52 \%$, respectively, relative to controls, but was not increased in membranes from $16-\mathrm{h}$ bile acid-loaded rats. Canalicular membrane 5' -nucleotidase and Mg ATPase also were increased.

These studies show that augmented bile acid flux through secreting liver causes an adaptive increase in bile acid-"independent" flow and in the activity of

This work was presented in part at the meetings of the American Association for the Study of Liver Disease held in November 1975 and in May 1976.

Dr. Wannagat's present address is Reginharstr. 30, D-506 Bensberg, Germany.

Received for publication 22 December 1976 and in revised form 3 October 1977. canalicular membrane enzymes. The mechanism by which bile acids modulate this and previously reported aspects of bile secretion remains to be elucidated.

\section{INTRODUCTION}

The formation of canalicular bile is regarded as having two components. The first, which is bile aciddependent, is attributed to the osmotic effect of bile acids and associated counterions secreted into the canalicular space (1). The second, which is bile acid-independent, is that volume which theoretically is secreted in the absence of bile acid secretion; it is derived by extrapolating the plot of bile volume as a function of bile acid secretion to zero bile acid secretion. The bile acid-independent fraction appears related to the activity of canalicular membrane $\mathrm{NaK}$ ATPase in a variety of experimental situations (1-5).

Recently, we reported studies involving two experimental models in which bile acid flux through secreting hepatocytes and overall bile secretion were increased. These experimental models are $(a)$ selective biliary obstruction, in which bile ducts draining two-thirds of the liver mass are obstructed while the remaining one-third continues to secrete bile at rates which are normal for the whole animal (6-9); and $(b)$ bile acid-loaded animals, in which all bile ducts are patent but the bile acid pool is expanded approximately twofold by means of the continuous intraduodenal infusion of taurocholate $(8,9)$. Although it is recognized that the liver has a reserve secretory capacity, which in these experimental circumstances undoubtedly was recruited into the secretory process, the fact that in both circumstances there was a significant and timedependent increase in bile acid transport maximum suggests that an adaptive change in the bile secretory mechanism had occurred.

In the present report, we describe the unexpected observation that bile acid-independent secretion, ex- 
pressed per mass of secreting parenchyma, was significantly increased in both selectively obstructed and bile acid-loaded animals. To elucidate the mechanism for this effect, we investigated the possibility that increased bile acid flux through the liver might lead to increased bile acid-independent flow through an effect on liver plasma membrane NaK-ATPase activity. These studies provide evidence that increased bile acid flux does indeed lead to an increase in the activity of plasma membrane enzymes, including NaK-ATPase. It is suggested that the "bile acid-independent" component of bile formation is not totally independent, but rather is significantly modulated by the flux of bile acids through the hepatocyte. Portions of these studies have been reported in preliminary communications $(8,10)$.

\section{METHODS}

Animals and operative procedures. Nonfasted male Sprague-Dawley rats were used in all experiments and were maintained on standard laboratory chow (Berkeley Standard Diet, Feedstuff Processing Company, San Francisco, Calif.). Selective obstruction of the bile ducts draining the median and left hepatic lobes, representing approximately two-thirds of the liver mass, was performed under ether anesthesia as described previously (6), and a PE 90 polyethylene catheter (Clay-Adams Div., Becton, Dickinson \& Co., Parsippany, N. J.) was placed in the duodenum. For studies of bile secretion in the whole animal (290-433 g), an exteriorized PE 90 choledochoduodenal catheter was placed to permit subsequent interruption of the enterohepatic circulation and collection of bile without additional operative stress $(8,9)$.

After operation, rats were maintained in restraining cages (11). Isotonic saline, $3 \mathrm{ml} / \mathrm{h}$, was administered via the duodenal catheter from 9 a.m. to 6 p.m. (light cycle), and $50 \mathrm{ml}$ of a liquid formula containing $7 \mathrm{~g}$ Dextri-Maltose No. 1 (Mead Johnson \& Co., Evansville, Ind.) and 3 g casein hydrolysate (Teklad Test Diets, Madison, Wis.) from 6 p.m. to 9 a.m. Control rats received intraduodenal feeding catheters and were similarly restrained. In some experiments, in rats with intact bile ducts, the bile acid pool was expanded by means of a continuous intraduodenal infusion of sodium taurocholate, $0.2 \mu \mathrm{mol} / \mathrm{min}$ per $100 \mathrm{~g}$ rat from the end of the operation to the beginning of the studies of bile secretion ( 16 or $48 \mathrm{~h}$ ). This rate of bile acid infusion was the approximate equivalent of one normal bile acid pool every $4 \mathrm{~h}(7,9)$ and after $48 \mathrm{~h}$ resulted in a twofold increase in bile acid pool and secretion rate (9). After $16 \mathrm{~h}$, bile acid pool and secretion rate were increased by approximately $35 \%(P<0.02){ }^{1}$

Studies of bile secretion and $\left[{ }^{14} \mathrm{C}\right]$ erythritol clearance. At the appropriate interval after operation, the exteriorized choledochoduodenal catheter was divided and bile was collected at 15 -min intervals for $2 \mathrm{~h}$ and at 30 -min intervals for a third hour. After measurement of volume, each fraction was diluted to $10 \mathrm{ml}$ in methanol and stored at $-20^{\circ} \mathrm{C}$. Bile flow averaged $2 \mathrm{ml} / \mathrm{h}$ during the $1 \mathrm{st} \mathrm{h}$ after division of the choledochoduodenal catheter and appeared to be stabilized during the bile collection period by continuation of the intraduodenal feeding, as shown previously by Strasberg et al. (12).

At the completion of bile secretory studies, the animals were sacrificed. In those rats subjected to selective biliary obstruction, the anatomy was verified by retrograde injection of india

\footnotetext{
1 Unpublished observations.
}

ink into the common bile duct as described previously (9). The livers were then removed and the right-caudate and medianleft lobes were weighed separately.

Bile acid-independent canalicular flow was determined for each animal by extrapolating the calculated linear regression of bile flow versus bile acid secretion to zero bile acid secretion. Mean values of slope and $y$-intercept (bile acidindependent flow) were calculated for each group. Biliary dead space, including bile passages (13) and catheter volume, was calculated to be $100 \mu \mathrm{l}$ or less and was small relative to sample volumes and secretory rates; correction for dead space did not significantly affect the experimental results.

The canalicular component of total bile flow was estimated by measuring the bile-to-plasma ratio of $\left[{ }^{14} \mathrm{C}\right]$ erythritol (14) by two different methods. In the first, three conscious, restrained, selectively obstructed rats received a pulse injection of $1 \mu \mathrm{Ci}$ of $\left[{ }^{14} \mathrm{C}\right]$ erythritol (Amersham/Searle Corp., Arlington Heights, Ill.) into the jugular vein, followed immediately by a constant infusion of $\left[{ }^{14} \mathrm{C}\right]$ erythritol at a rate of $1 \mu \mathrm{Ci} / \mathrm{h}$ for the balance of the experiment. After a 1-h stabilization period, bile was collected at $30-\mathrm{min}$ intervals for $4 \mathrm{~h}$ and volumes were measured. Blood samples $(100 \mu \mathrm{l})$ were obtained from the tail vein at the midpoints of the bile collection periods. In the second method for determination of bile to plasma erythritol ratios $(4,14)$, rats were anesthetized with i.v. pentobarbitol ( 10 $\mathrm{mg} / 100 \mathrm{~g}$ body weight), both renal pedicles were ligated, and a $1-\mu \mathrm{Ci}$ pulse of tracer $\left[{ }^{14} \mathrm{C}\right]$ erythritol was administered via the jugular vein. After a 20 -min stabilization period, bile was collected at 10 -min intervals for $1 \mathrm{~h}$ and $100-\mu$ l blood samples were collected from the tail vein in heparinized capillary tubes at the midpoint of each bile collection period as described above.

Measured aliquots of bile and plasma were then added to 15 $\mathrm{ml}$ of Liquifluor-toluene (New England Nuclear, Boston, Mass.) containing Biosolv BBS-3 (Beckman Instruments, Inc., Fullerton, Calif.) and were assayed for radioactivity in a Beckman LS-250 liquid scintillation system (Beckman Instruments, Inc.), using an automatic external standard for quench correction. Bile-to-plasma ratios of $\left[{ }^{14} \mathrm{C}\right]$ erythritol were calculated for all periods of collection; in individual experiments, ratios agreed within $5 \%$.

Preparation of liver plasma membranes. Liver plasma membranes were prepared from control, selectively obstructed, and bile acid-loaded rats (213-272 g) by discontinuous sucrose density gradient centrifugation by a modification of the methods of Song et al. (15) and Boyer and Reno (16). These animals had not been used for studies of bile secretion. Rats were sacrificed by decapitation; the livers were removed and immediately immersed in ice-cold $1 \mathrm{mM}$ ethyleneglycol-bis-( $\beta$-amino-ethyl ether) $N, N^{\prime}$-tetraacetic acid (EGTA) in $1 \mathrm{mM} \mathrm{NaHCO}_{3}, \mathrm{pH}$ 7.5. The livers were blotted, weighed, and subjected to the following procedures, all carried out at $4^{\circ} \mathrm{C}$ and employing solutions prepared with glass distilled water. Livers were perfused with buffer ( $1 \mathrm{mM}$ EGTA in $1 \mathrm{mM} \mathrm{NaHCO}_{3}, \mathrm{pH}$ 7.5) and were reweighed, minced, and homogenized in $2 \mathrm{vol}$ of buffer in a loose-fitting Dounce homogenizer, using 15 gentle up-and-down strokes. A 2-ml sample of homogenate was saved for enzyme assays; the remainder was diluted to approximately $200 \mathrm{ml}$ with buffer filtered twice through surgical gauze and centrifuged for $10 \mathrm{~min}$ at $100 \mathrm{~g}$ in a Sorvall RC-2-B refrigerated centrifuge. The supernate was saved; the pellet, containing debris and unbroken cells, was washed with buffer and recentrifuged. This supernate was combined with the initial supernate and recentrifuged at $1,500 \mathrm{~g}$ for $10 \mathrm{~min}$ to obtain a crude membrane pellet. This pellet was washed and recentrifuged four times and then diluted in buffer to a volume approximately one-third that of the original liver tissue. 
Exactly $5.5 \mathrm{vol}$ of $70 \%$ sucrose $\left(d_{4}=1.26 \mathrm{~g} / \mathrm{ml}\right)$ was added to the membranes which were suspended evenly by gentle stirring. $25-26 \mathrm{ml}$ of the resulting suspension was transferred to a $60-\mathrm{ml}$ cellulose nitrate tube (Beckman Instruments, Inc., Spinco Div., Palo Alto, Calif.) and carefully overlayed with 17 $\mathrm{ml}$ of sucrose solution, $d_{4}=1.18 \mathrm{~g} / \mathrm{ml}$, and $14 \mathrm{ml}$ of sucrose solution, $d_{4}=1.15 \mathrm{~g} / \mathrm{ml}$, prepared by appropriate dilution of the $d_{4}=1.26 \mathrm{~g} / \mathrm{ml}$ solution. The gradient tube was then centrifuged in a type 25.2 swinging bucket rotor at $66,000 \mathrm{~g}$ for $2 \mathrm{~h}$ in a Beckman L3-50 ultracentrifuge at $4^{\circ} \mathrm{C}$. Liver plasma membranes were recovered from the $d 1.15$ to $d 1.18$ interface, diluted with 4-5 vol of buffer, and centrifuged at 7,000 $\mathrm{g}$ for 10 $\mathrm{min}$. The pellet was diluted with $20 \mathrm{vol}$ of buffer, recentrifuged $(1,500 \mathrm{~g}, 10 \mathrm{~min})$, and finally resuspended in glass-distilled water to a final concentration of $1-2 \mathrm{mg}$ of protein per $\mathrm{ml}$, as determined by the method of Lowry et al. (17), using human serum albumin (Schwartz-Mann Div., Becton, Dickinson \& Co., Orangeburg, N. Y.) as a standard.

In the studies of selectively obstructed rats and their respective controls, the membrane preparation procedure employed differed slightly from the foregoing as follows: $(a)$ EDTA was used instead of EGTA. (b) the 10-min, 100-g centrifugation of the filtered homogenate was omitted; $(c)$ the initial 1,500-g pellet was not washed and was resuspended in a volume of buffer equal to that of the original liver tissue; and $(d)$ the membranes recovered from the $d 1.15$ to $d 1.18$ interface were diluted in buffer and centrifuged twice at $1,500 \mathrm{~g}$. These modifications, largely necessitated by the smaller quantities of tissue available, did not significantly affect the purity of the recovered membrane fractions.

Analytical methods. Lipids were extracted from biological samples according to the method of Folch et al. (18) Cholesterol was quantified in a Hewlett-Packard 402B gas chromatograph, using a $4-\mathrm{ft}$ column of $3.8 \%$ silicone gum rubber (UC-W982, Hewlett-Packard Co., Avondale Div., Avondale, Pa.) on 100/120 mesh Gas-Chrom Q, Applied Science Laboratories Inc., Inglewood, Calif.) at an oven temperature of $230^{\circ} \mathrm{C} ; 5$ - $\alpha$-cholestane was used as the internal standard, and peak areas were calculated by a HewlettPackard model 3380 digital integrator. Phospholipid was measured by the method of Bartlett (19), as modified by Marinetti (20). Total bile acids were determined enzymatically with purified 3- $\alpha$-hydroxysteroid dehydrogenase (Worthington Biochemical Corp., Freehold, N. J.) by the method Talalay (21), as modified by Admirand and Small (22).

ATPase assay. Homogenates and liver plasma membrane preparations were assayed for ATPase activity in duplicate or triplicate incubations after overnight storage at $4^{\circ} \mathrm{C}$, according to the method of Ismail-Beigi and Edelman (23), modified to

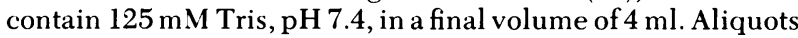
$(100 \lambda)$ of either $3-4 \mathrm{mg}$ of homogenate protein or $100-200 \mu \mathrm{g}$ of liver plasma membrane protein were preincubated in the reaction medium $(3.8 \mathrm{ml})$ for $10 \mathrm{~min}$ at $37^{\circ} \mathrm{C}$ on a Metabolyte water bath shaker (New Brunswick Scientific Co., Inc., New Brunswick, N. J.) at 200 oscillations per min.

The reaction was started with the addition of $100 \mu \mathrm{l}$ of 200 $\mathrm{mM}$ disodium ATP (Sigma Chemical Co., St. Louis, Mo.) in $100 \mathrm{mM} \mathrm{MgCl}$, and was terminated by the addition of $1 \mathrm{ml}$ TCA (35\% wt/vol) and immediately chilled on ice. Sodium azide was included in all assays to prevent regeneration of ATP. Ouabain ( $1 \mathrm{mM}$ ) was used in parallel duplicate or triplicate incubations to estimate NaK-ATPase activity as the difference between total ATPase and ouabain-insensitive ATPase (i.e., Mg ATPase). Our results, as well as those obtained by others employing rat liver plasma membrane fractions $(16,24)$ and rat liver homogenates (25), showed that the ouabain-inhibitable component of ATPase activity is equal to that activity which is lost when $\mathrm{Na}^{+}$or $\mathrm{K}^{+}$is omitted from the reaction mixture. Accordingly, ouabain-inhibitable ATPase activity is regarded as equivalent to NaK-ATPase activity (23).

Blank incubations were taken at zero time, following the usual 10-min preincubation and "termination" by the addition of ice-cold TCA, after which the contents of the incubation flask were stirred vigorously, substrate (ATP) added and the flask chilled on ice. After termination, all samples were centrifuged at $25,000 \mathrm{~g}$ for $10 \mathrm{~min}$. $2-\mathrm{ml}$ aliquots of supernatant were analyzed for inorganic phosphate by Bartlett's modification (19) of the Fiske-Subbarow method (26). The ATPase reactions were linear to $30 \mathrm{~min}$ and over a range of $48-200 \mathrm{~g}$ membrane protein per incubation.

Other enzyme assays. 5'-nucleotidase activity was determined under the same conditions as those employed in the assays for total ATPase activity, except that 5'-AMP, final concentration $5 \mathrm{mM}$, was substituted for ATP $(23,27)$. The formation of inorganic phosphate was measured as described above. The reaction was linear to $30 \mathrm{~min}$; standard incubations were carried out over $15 \mathrm{~min}$.

Succinate-cytochrome $\mathrm{C}$ reductase, a mitochondrial marker, was assayed as cytochrome $\mathrm{C}$ reduced, according to the method of Tisdale (28), modified in that disodium succinate (Calbiochem, San Diego, Calif.) rather than the potassium salt was employed, and that the reaction was started by the addition of substrate. Blank incubations lacked substrate.

NADPH-cytochrome $\mathrm{C}$ reductase, a microsomal marker, was measured as cytochrome $\mathrm{C}$ reduced by the method of Masters et al. (29), modified in that the incubation medium contained $0.1 \mathrm{M}$ phosphate buffer and $0.01 \mathrm{M}$ EDTA, and that the reaction was carried out at $37^{\circ} \mathrm{C}$.

Statistical methods. Significance of differences among various experimental groups was determined by the paired or unpaired $t$ test, and correlations and linear regression analyses were carried out by standard methods (30).

\section{RESULTS}

Relationship of bile volume and bile acid secretion in rats with selective biliary obstruction. Bile volume and bile acid secretion were measured in 15-min samples of bile collected after nonoperative interruption of the enterohepatic circulation in control and selectively obstructed rats $48 \mathrm{~h}$ after operation, as described in Methods. The volume and total bile acid content of each sample, expressed per minute per $100 \mathrm{~g}$ body weight, is shown in Fig. 1. As previously reported $(8,9)$, volume and bile acid secretion rates per $100 \mathrm{~g}$ of rat were similar in the two groups. Despite obstruction of the bile ducts draining two-thirds of the hepatic parenchymal mass in the selectively obstructed rats, it can be seen that both bile acid-dependent secretion (represented by the slope of the linear regression) and bile acid-independent secretion (representing the extrapolation of this regression to zero bile acid output) were essentially unaffected. However, when the same experimental results were expressed per gram of nonobstructed liver, bile acid-independent flow in selectively obstructed animals was increased approximately threefold, relative to controls (Fig. 2). Thus, bile acid-independent flow in selective biliary obstruction is maintained at a rate which is normal for the whole animal because of increased secretion by the nonob- 


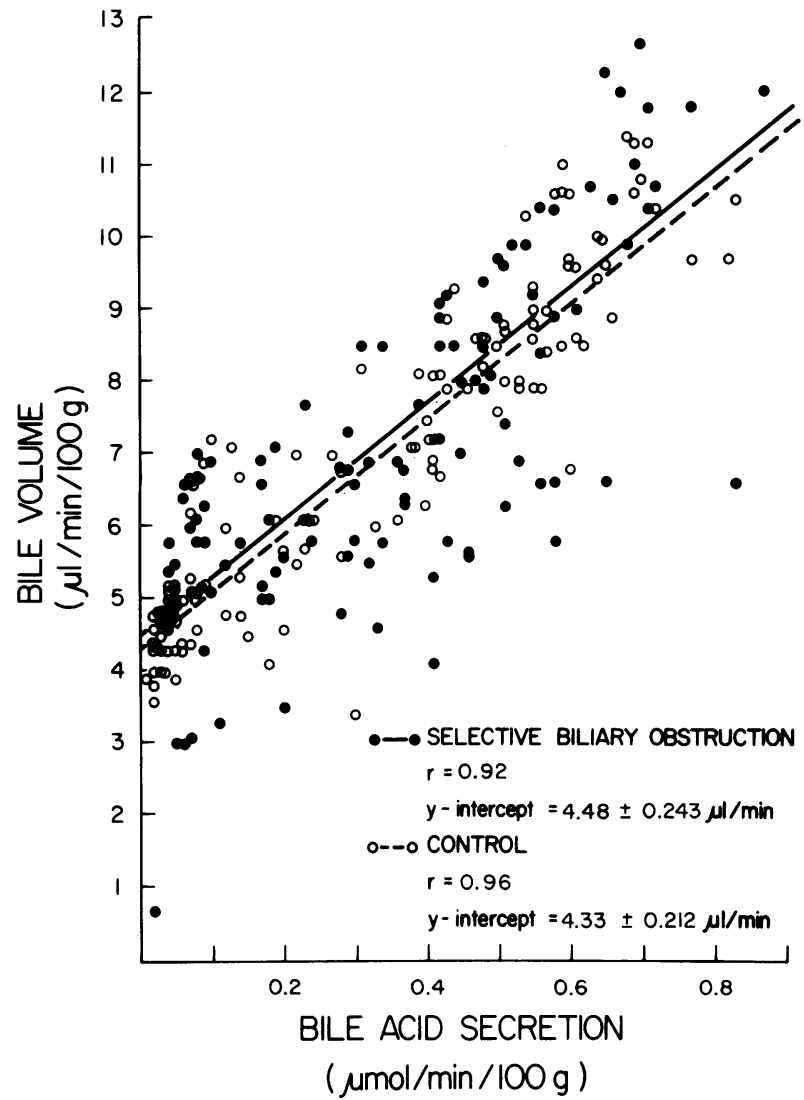

FIGURE 1 Relationship of bile volume and bile acid secretion in controls and in rats with selective biliary obstruction. Controls and selectively obstructed rats were prepared with exteriorized choledochoduodenal catheters to preserve the enterohepatic circulation and were maintained in restraining cages for $48 \mathrm{~h}$ after operation, as described in Methods. After division of the choledochoduodenal catheter, bile was collected at 15-min intervals for a total of $3 \mathrm{~h}$ and was analyzed for volume and bile acid content, expressed per $100 \mathrm{~g}$ body weight. All samples from seven control and seven selectively obstructed rats are plotted. Linear regressions were calculated by the method of least squares for each animal. The plotted lines, representing the mean slope and intercept for each group, do not differ significantly.

structed lobes. Bile acid-dependent flow, i.e., the slope of the linear regression, was not affected.

The possibility that enhanced bile acid-independent secretion resulted from increased bile acid flux through nonobstructed lobes was considered. This inference also was suggested by evidence that bile acid pool and overall bile acid secretion rate was unaffected in selectively obstructed rats $(8,9)$, implying that the overall secretory load is handled by the remaining nonobstructed parenchymal mass. To test this possibility, the bile acid pool of rats with intact bile ducts was expanded by a 48 -h intraduodenal taurocholate infusion (see Methods), approximately doubling the bile acid pool and secretion rate $(8,9)$. Bile acid-dependent and bile acid-independent volume flow were measured as described above. The results are shown in Fig. 3. In bile acid-loaded animals, there was a slight increase in the slope of the regression line, i.e., in bile aciddependent flow, per $100 \mathrm{~g}$ of rat. Moreover, there was a highly significant $(P<<0.0001) 50 \%$ increase in the vertical intercept, i.e., in bile acid-independent flow. The results were similar when expressed per gram of liver ( $43 \%$ increase relative to controls; $P<0.001$ ).

Thus, in two experimental models in which bile acid flux through secreting hepatic parenchyma was increased over $48 \mathrm{~h}$, there was a corresponding increase in bile acid-independent flow. This might be the result of either of two general mechanisms. First, it could represent the immediate effect of secretion of an increased bile acid mass, suggesting rapid recruitment into the secretory process of centrilobular hepatocytes which normally are less active (31). Alternatively, it might represent a more general adaptive change affecting the secreting parenchyma, in which case the effect might be expected to exhibit a latent period.

To examine this question, an additional group of

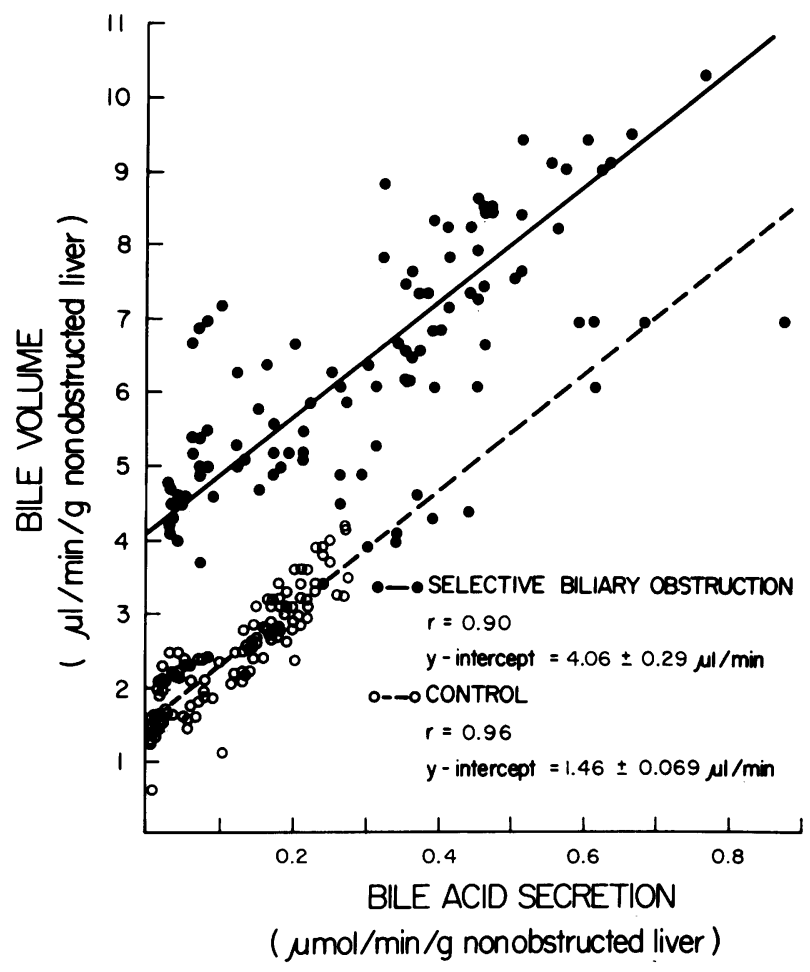

FIGURE 2 Relationship of bile volume and bile acid secretion in controls and in rats with selective biliary obstruction. Rates of bile volume and bile acid secretion shown in Fig. 1 are expressed per gram of nonobstructed liver, rather than per 100 $\mathrm{g}$ body weight. Slopes of the linear regressions do not differ significantly, but the difference in vertical intercepts is highly significant $(P \ll 0.0001)$. 


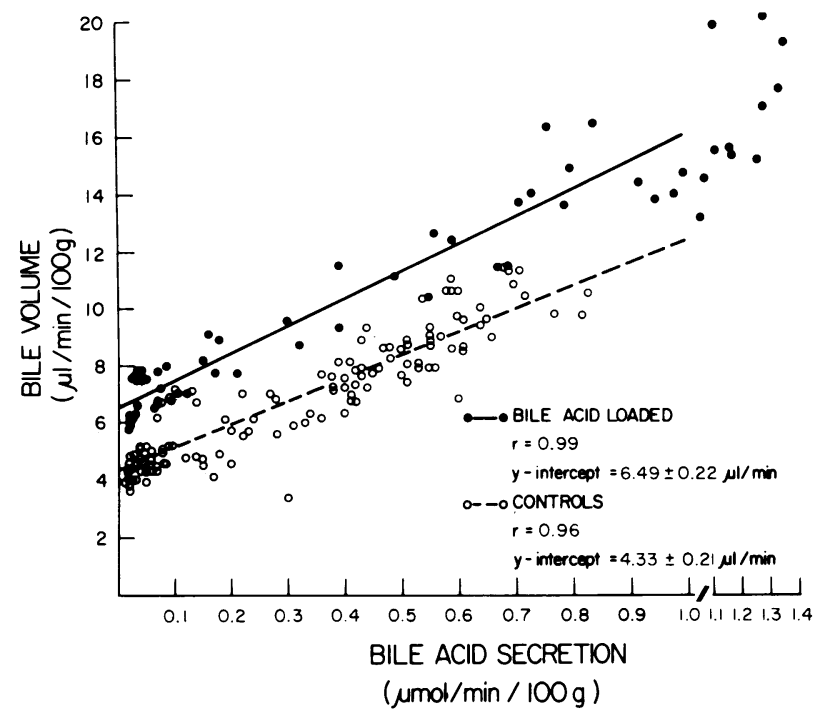

FIGURE 3 Effect of 48-h bile acid loading on relationship of bile volume and bile acid secretion. Rats with patent bile ducts were prepared with exteriorized choledochoduodenal catheters and maintained in restraining cages for $48 \mathrm{~h}$ after operation as described in Fig. 1 and Methods. Bile acid-loaded rats received a 48 -h intraduodenal infusion of taurocholate, 0.2 $\mu \mathrm{mol} / \mathrm{min}$ per $100 \mathrm{~g}$. After division of the choledochoduodenal catheter, bile was collected at intervals for $3 \mathrm{~h}$ from seven control and six bile acid-loaded rats; results are plotted per 100 $\mathrm{g}$ body weight. For bile acid-loaded animals, there is a significant increase in both slope $(19 \%, P<0.05)$ and in vertical intercept $(50 \%, P \ll 0.0001)$, compared with controls.

animals with patent bile ducts was studied to which bile acids were administered at the same rate for only $16 \mathrm{~h}$, producing an increase in both bile acid pool size and secretion rate of approximately 35\%. Controls were infused with saline. The results are shown in Fig. 4. Despite continuous intraduodenal taurocholate infusion over a 16 -h interval, there was no significant effect either on the slope of the line (bile acid-dependent flow) or on the vertical intercept (bile acid-independent flow). The results were similar when expressed per gram of secreting liver. These experiments suggest that the bile acid-induced increase in bile acid-independent flow may be time-dependent, but a possible effect of differences in bile acid pool and secretion rate between the 16-h and 48-h animals is not excluded.

Studies of $\left[{ }^{14} \mathrm{C}\right]$ erythritol secretion. To examine the possibility that the increase in bile acid-independent flow resulted from ductal secretion, the secretion of $\left[{ }^{14} \mathrm{C}\right]$ erythritol, a marker of canalicular bile flow, was examined in controls, selectively obstructed, and bile acid-loaded animals $48 \mathrm{~h}$ after operation. The results are shown in Table I. Under all conditions the bile-toplasma $\left[{ }^{14} \mathrm{C}\right]$ erythritol ratios approximated 1.0 , suggesting that virtually all bile was canalicular in origin. Therefore, the augmented bile acid-independent flow

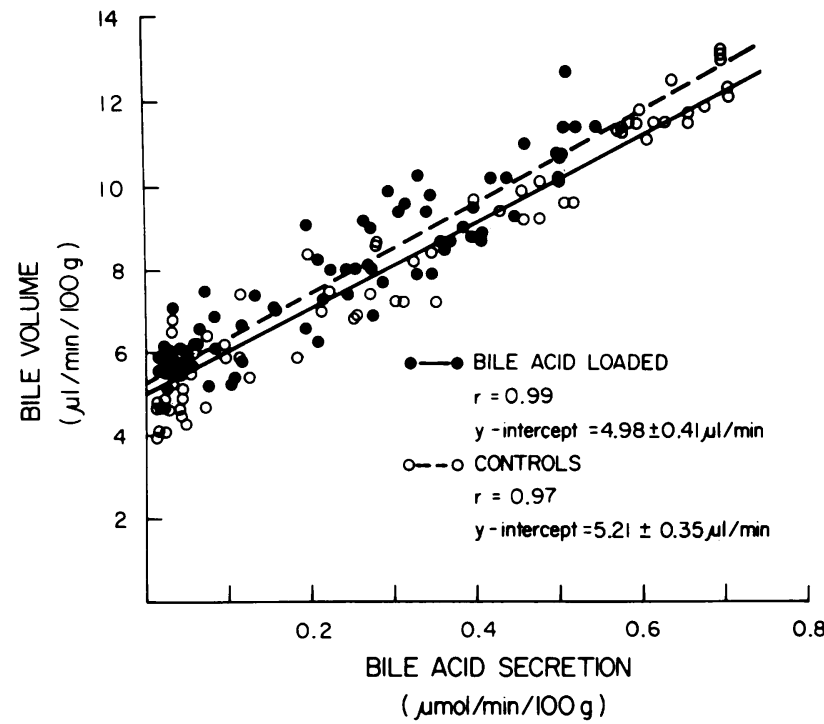

FIGURE 4 Effect of 16-h bile acid loading on relationship of bile volume and bile acid secretion. Bile samples from bile acid-loaded and control rats were analyzed for volume and bile acid secretion per $100 \mathrm{~g}$ body weight after division of the choledochoduodenal catheter as described in Fig. 3 and Methods, except that rats were studied after $16 \mathrm{~h}$ of bile acid loading. Individual values for six control and five bile acid-loaded rats are presented. There was no significant differences in slope or vertical intercept.

was regarded as reflecting changes in canalicular secretion.

Studies of enzyme activity in canaliculi-enriched liver plasma membranes. Since bile acid-independent canalicular secretion of water has been attributed to the activity of canalicular membrane NaK-ATPase, the activities of this and other liver plasma membrane enzymes were examined under the experimental conditions described above. Comparisons among homogenates and liver plasma membranes from control animals are shown in Table II. Similar to the observations of other investigators $(16,32)$, the canalicular membrane markers, NaK-ATPase, 5'nucleotidase, and Mg ATPase, were all enriched in the

TABLE I

Biliary Secretion of $\left[{ }^{14} \mathrm{C}\right]$ Erythritol

\begin{tabular}{lll}
\hline & & Bile ${ }^{14} \mathrm{C}$ :Serum ${ }^{14} \mathrm{C}$ \\
\hline Controls & $(n=2)$ & $1.00(0.98,1.02)$ \\
Selective biliary obstruction & $(n=5)$ & $1.02(0.98-1.03)$ \\
Bile acid-loaded & $(n=2)$ & $1.02(1.01,1.03)$
\end{tabular}

$\left[{ }^{14} \mathrm{C}\right]$ Erythritol was measured in plasma and bile of controls, selectively obstructed, and bile acid-loaded rats $48 \mathrm{~h}$ after operation as described in Methods. Shown are group means, and individual values or ranges, expressed as bile-to-serum ${ }^{14} \mathrm{C}$ ratio. 
TABLE II

Enzyme Specific Activities in Rat Liver Homogenates and Plasma Membranes

\begin{tabular}{lccccc}
\hline & NaK-ATPase & $\begin{array}{c}5^{\prime} \text {-nucleo- } \\
\text { tidase }\end{array}$ & Mg ATPase & $\begin{array}{c}\text { Succinate cytochrome } \\
\text { C reductase }\end{array}$ & $\begin{array}{c}\text { NADPH cytochrome } \\
\text { C reductase }\end{array}$ \\
\hline \multicolumn{2}{c}{$\mu$ mol $P_{i}$ released/mg protein per $h$} & nmol cytochrome C reduced/mg protein per min \\
Homogenate & $0.79 \pm 0.03$ & $3.06 \pm 0.09$ & $2.04 \pm 0.06$ & $48.4 \pm 5.5$ & $92.4 \pm 10.1$ \\
Plasma membranes & $11.3 \pm 0.8$ & $22.3 \pm 2.2$ & $21.4 \pm 1.7$ & $32.1 \pm 4.3$ & $19.1 \pm 2.3$ \\
Ratio $(\mathrm{LPM} / \mathrm{H})$ & 14.4 & 7.30 & 10.5 & 0.66 & 0.21 \\
\hline
\end{tabular}

Liver plasma membranes were prepared from control rats $48 \mathrm{~h}$ after operation and were analyzed for NaK-ATPase, Mg ATPase, and 5'-nucleotidase and for succinate-cytochrome $C$ reductase and NADPH cytochrome $\mathrm{C}$ reductase as described in Methods. Results are expressed for whole homogenate and for plasma membranes, and as the ratio of membranes (LPM) to homogenate $(\mathrm{H})$. Shown are means $\pm \mathrm{SE}$ for 8 animals, except for LPM NaK- and Mg ATPase $(n=17)$.

liver plasma membranes, while the activities of succinate-cytochrome $\mathrm{C}$ reductase, a mitochondrial marker, and NADPH-cytochrome $\mathrm{C}$ reductase, a microsomal marker, were diminished relative to homogenate activity. The activity of NaK-ATPase is similar to that reported by Boyer and Reno (16) and by Layden and Boyer (4). Although 5'-nucleotidase was only 7.3-fold enriched, while others have obtained 18- or 19 -fold enrichment $(16,32)$, the relative purification of the liver plasma membrane preparations did not differ significantly between respective control and experimental animals in any of the groups studied. Thus, as shown in Table III, mitochondrial and microsomal contamination, as indicated by the activities of the marker enzymes, was similar in the membranes prepared from both right and median lobes of the control and selectively obstructed rats, and from whole livers of controls and bile acid-loaded rats. The fact that relative enrichment of NaK-ATPase activity was greater in 48-h whole liver controls (16.2) than in the median and right lobes of the controls for the selectively obstructed group (8.9 and 12.4 , respectively) may reflect the modifications in technique which were necessitated by the smaller quantities of tissue available (Methods). The relative "enrichment" in canalicular membrane enzymes in the right lobe of selectively obstructed rats and in the 48-h bile acid-infused rats in consistent with the observed increase in specific activity of these enzymes (see below). In Table IV are shown plasma membrane yields for the various groups.

TABLE III

Relative Enzyme Enrichment in Liver Plasma Membrane Preparations

\begin{tabular}{|c|c|c|c|c|c|c|c|c|c|c|}
\hline & \multicolumn{2}{|c|}{ NaK-ATPase } & \multicolumn{2}{|c|}{$5 '$-nucleotidase } & \multicolumn{2}{|c|}{ Mg ATPase } & \multicolumn{2}{|c|}{$\begin{array}{c}\text { Succinate cytochrome } \\
\text { C. reductase }\end{array}$} & \multicolumn{2}{|c|}{$\begin{array}{l}\text { NADPH cytochrome } \\
\text { C reductase }\end{array}$} \\
\hline & Median & Right & Median & Right & Median & Right & Median & Right & Median & Right \\
\hline Control vs. SBO* & \multicolumn{10}{|c|}{ Ratio of membrane to homogenate activity } \\
\hline \multicolumn{11}{|l|}{$48 \mathrm{~h}$} \\
\hline Control $(n=3)$ & $8.9 \pm 1.8$ & $12.4 \pm 3.2$ & $6.91 \pm 1.63$ & $7.22 \pm 1.99$ & $9.72 \pm 1.21$ & $7.75 \pm 1.89$ & $0.62 \pm 0.21$ & $0.56 \pm 0.20$ & $0.16 \pm 0.03$ & $0.26 \pm 0.04$ \\
\hline $\operatorname{SBO}(n=3)$ & $10.0 \pm 1.1$ & $21.5 \pm 2.0$ & $7.70 \pm 0.27$ & $12.0 \pm 0.70$ & $8.30 \pm 0.65$ & $17.70 \pm 3.60$ & $0.83 \pm 0.28$ & $0.50 \pm 0.33$ & $0.24 \pm 0.01$ & $0.28 \pm 0.01$ \\
\hline \multicolumn{11}{|l|}{ Control vs. bile } \\
\hline \multicolumn{11}{|l|}{$48 \mathrm{~h}$} \\
\hline Bile acid-loaded & \multicolumn{2}{|c|}{$16.2 \pm 1.1$} & \multicolumn{2}{|c|}{$7.44 \pm 0.38$} & \multicolumn{2}{|c|}{$9.98 \pm 0.73$} & \multicolumn{2}{|c|}{$0.80 \pm 0.20$} & \multicolumn{2}{|c|}{$0.21 \pm 0.01$} \\
\hline$(n=5)$ & \multicolumn{2}{|c|}{$23.8 \pm 2.41$} & \multicolumn{2}{|c|}{$9.64 \pm 0.78 \$$} & \multicolumn{2}{|c|}{$14.90 \pm 2.2$} & \multicolumn{2}{|c|}{$0.65 \pm 0.13$} & \multicolumn{2}{|c|}{$0.29 \pm 0.02^{\prime \prime}$} \\
\hline \multicolumn{11}{|l|}{$16 \mathrm{~h}$} \\
\hline Bile acid-loaded & \multicolumn{2}{|c|}{$17.7 \pm 1.1$} & \multicolumn{2}{|c|}{$9.03 \pm 0.29$} & \multicolumn{2}{|c|}{$10.1 \pm 1.0$} & \multicolumn{2}{|c|}{$0.59 \pm 0.24$} & \multicolumn{2}{|c|}{$0.24 \pm 0.0 .3$} \\
\hline$(n=6)$ & \multicolumn{2}{|c|}{$14.9 \pm 0.5 \S$} & \multicolumn{2}{|c|}{$8.50 \pm 0.59$} & \multicolumn{2}{|c|}{$12.2 \pm 1.0$} & \multicolumn{2}{|c|}{$0.62 \pm 0.22$} & \multicolumn{2}{|c|}{$0.20 \pm 0.02$} \\
\hline
\end{tabular}

Liver plasma membranes and homogenates were prepared and analyzed for enzyme activity as described in Methods. Results are expressed as the ratio of enzyme activity in the membrane to that in the homogenate. Mean $\pm S E$.

* SBO, rats with selective biliary obstruction.

$\downarrow P=<0.02$. vs. control.

$\$ P=<0.05$ vs. control.

" $P=<0.01$ vs. control. 
TABLE IV

Liver Plasma Membrane Yield

\begin{tabular}{lcc}
\hline & Median lobe & Right lobe \\
\hline & \multicolumn{2}{c}{$m g / g$ liver } \\
Control vs. SBO* & \\
$48 \mathrm{~h}$ & $0.336 \pm 0.043$ & $0.520 \pm 0.095$ \\
Control $(n=5)$ & $0.319 \pm 0.074$ & $0.579 \pm 0.086$ \\
SBO $(n=5)$ & \\
Control vs. bile acid-loaded & \\
48 h & $0.272 \pm 0.103$ \\
Control $(n=5)$ & $0.332 \pm 0.117$ \\
Bile acid-loaded $(n=8)$ & \\
16 h & \\
Control $(n=6)$ & $0.412 \pm 0.022$ \\
Bile acid-loaded $(n=6)$ & $0.323 \pm 0.039$ \\
\hline
\end{tabular}

Plasma membranes were prepared and analyzed for protein as described in Methods. Mean $\pm S E$. None of the differences between experimental and respective control values are statistically significant.

* SBO, rats with selective biliary obstruction.

Again, there are no differences between the respective control and experimental tissues; the basis for the increased yield from the right lobes (similar in control and selectively obstructed rats) is not apparent.

The effect of selective biliary obstruction on liver plasma membrane enzymes, measured at $48 \mathrm{~h}$ after operation, is shown in Table V and Fig. 5. Several important findings were noted. First, there were no significant differences in the activity of NaK-ATPase, 5 '-nucleotidase, or Mg ATPase between median and right lobes in the control group. Second, in the median (obstructed) lobe of selectively obstructed animals, activities of NaK-ATPase and 5'-nucleotidase were not changed, while Mg ATPase was decreased. Finally, in the right (bile-secreting) lobe of selectively obstructed

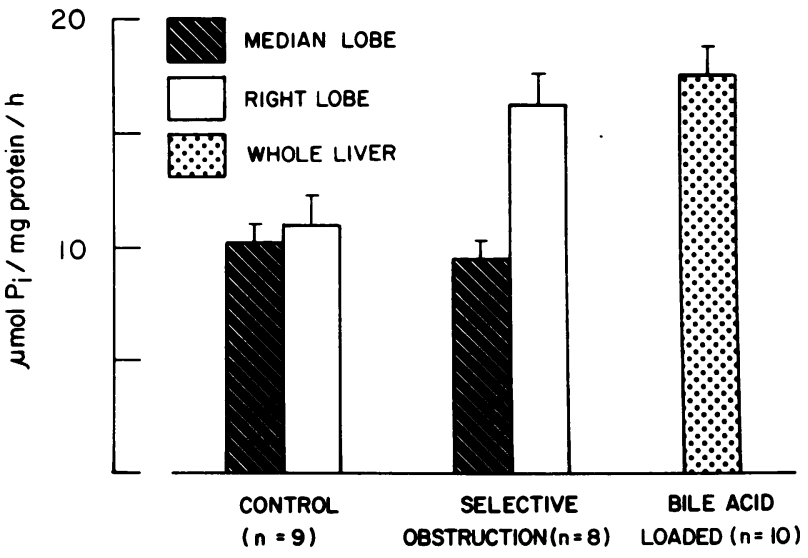

FIGURE 5 Effect of 48-h selective biliary obstruction and bile acid pool expansion on liver plasma membrane Na-K ATPase activity. Liver plasma membranes were prepared from the indicated lobes of livers of control, selectively obstructed, and bile acid-loaded rats, and were analyzed for $\mathrm{Na}-\mathrm{K}$ ATPase activity as described in Methods. Activity in the right (bile-secreting) lobe of selectively obstructed rats is significantly greater than both the right lobes in control animals $(47 \%$ increased, $P=0.02)$ and the obstructed median lobes in the same animals $(71 \%$ greater, $P \ll 0.0001)$. Similar changes were observed in 48 -h bile acid-loaded rats $(52 \%$ increase versus controls, $P<0.001$ ).

animals there was a significant increase in the activity of NaK-ATPase relative to both the right lobe in control animals $(47 \%, P \simeq 0.02)$ and to the obstructed median lobe in selectively obstructed animals $(71 \%, P$ $\ll 0.0001)$. Similar changes were noted in the activity of 5 '-nucleotidase, but these differences were not statistically significant. In the case of $\mathrm{Mg}$ ATPase, the slight increase in activity observed in the bilesecreting right lobe of selectively obstructed animals was not statistically significant.

Similar comparisons were carried out between control liver plasma membranes and those obtained

TABLE V

Activities of Liver Plasma Membrane Enzymes at $48 \mathrm{~h}$ from Control and Selectively Obstructed Rats

\begin{tabular}{|c|c|c|c|c|c|c|}
\hline & \multicolumn{2}{|c|}{ NaK-ATPase } & \multicolumn{2}{|c|}{5 '-nucleotidase } & \multicolumn{2}{|c|}{ Mg ATPase } \\
\hline & Median lobe & Right lobe & Median lobe & Right lobe & Median lobe & Right lobe \\
\hline & \multicolumn{6}{|c|}{$\mu m o l P_{i}$ released/mg protein per $h$} \\
\hline Controls & $10.1 \pm 0.9$ & $10.9 \pm 1.3$ & $23.0 \pm 5.0$ & $24.3 \pm 7.3$ & $21.8 \pm 1.9$ & $22.1 \pm 3.2$ \\
\hline SBO & $9.4 \pm 0.8$ & $16.0 \pm 1.5^{*}$ & $26.3 \pm 4.2$ & $37.2 \pm 3.1$ & $15.6 \pm 2.1 \S$ & $29.1 \pm 3.0$ \\
\hline
\end{tabular}

Liver plasma membranes were prepared from control and selectively obstructed (SBO) rats and were assayed for enzyme activities $48 \mathrm{~h}$ after operation as described in Methods. Mean $\pm \mathrm{SE}$ for groups of 9 (controls), 8 (SBO), and 3 (5'-nucleotidase, both control and SBO).

$* P<0.05$ vs. control right lobe.

$\neq P \ll 0.0001$ vs. SBO median lobe.

$\S P<0.05$ vs. control median lobe, and $P<0.0005$ vs. SBO right lobe. 
from rats with patent bile ducts and expanded bile acid pools after $48 \mathrm{~h}$ of bile acid loading. The results are shown in Table VI and Fig. 5. As in the bile-secreting nonobstructed lobe of rats with selective biliary obstruction, there was a significant increase $(52 \%$, $P<0.001)$ in liver plasma membrane NaK-ATPase relative to controls. Significant increases in the activities of 5'-nucleotidase and Mg ATPase were also observed. These changes were observed despite an apparent increase in microsomal contamination of the plasma membrane preparation under these conditions. In contrast to these findings at $48 \mathrm{~h}$, it can be seen (Table VII) that after only $16 \mathrm{~h}$ of bile acid loading, activities of the three enzymes were not increased. To the contrary, canalicular membrane NaK-ATPase activity was slightly, but significantly, less than that in the 16-h controls. In none of the experimental groups was there a significant change in the activity of NaK-ATPase in whole homogenate, relative to controls. The possible implications of this observation are considered below.

\section{DISCUSSION}

In selective biliary obstruction, the remaining onethird of the liver parenchymal mass which is not obstructed secretes an essentially normal bile acid pool at rates which for the whole liver or whole animal are normal $(7,9)$. In relation to the reduced mass of secreting parenchyma, however, bile acid secretion is increased two-to-threefold compared with controls, and this increase is accompanied by an increase in taurocholate secretory transport maximum $(8,9)$. In bile acid loading, rats with patent bile ducts are subjected to expansion of the bile acid pool over $48 \mathrm{~h}$ to approximately twice normal, associated with an approximate doubling of bile acid secretion rate. As with selective obstruction, increased bile acid secretion in bile

TABLE VI

Activities of Liver Plasma Membrane Enzymes from 48-h Controls and Bile Acid-Loaded Rats

\begin{tabular}{lccc}
\hline & NaK-ATPase & $\begin{array}{c}\text { 5'-nucleo- } \\
\text { tidase }\end{array}$ & Mg ATPase \\
\hline \multicolumn{4}{c}{$\mu$ mol $P_{i}$ released/mg protein per $h$} \\
$\begin{array}{l}\text { Controls }(n=14) \\
\begin{array}{l}\text { Bile acid-loaded } \\
(n=10)\end{array}\end{array}$ & $11.3 \pm 0.8$ & $22.3 \pm 2.2$ & $21.4 \pm 1.7$ \\
\hline
\end{tabular}

Liver plasma membranes were prepared from control and bile acid-loaded rats at $48 \mathrm{~h}$ after operation, and were analyzed for enzyme activities as described in Methods. Mean \pm SE. (The control $5^{\prime}$-nucleotidase group consists of 8 animals.)

${ }^{*} P<0.001$ vs. controls.

$\$ P<0.05$ vs. controls.

$\S P<0.002$ vs. controls.
TABLE VII

Activities of Liver Plasma Membrane Enzymes from $16 \mathrm{~h}$ Controls and Bile Acid-Loaded Rats

\begin{tabular}{lccc}
\hline & NaK-ATPase & $\begin{array}{c}\text { 5'-nucleo- } \\
\text { tidase }\end{array}$ & Mg ATPase \\
\hline & \multicolumn{3}{c}{$\mu$ mol $P_{\text {i }}$ released/mg protein per $h$} \\
Controls $(n=6)$ & $14.4 \pm 1.2$ & $21.7 \pm 0.6$ & $21.0 \pm 2.4$ \\
$\begin{array}{l}\text { Bile acid-loaded } \\
(n=6)\end{array}$ & $11.4 \pm 0.6^{*}$ & $22.1 \pm 2.1$ & $25.1 \pm 3.6$ \\
\hline
\end{tabular}

Liver plasma membranes were prepared from control and bile acid-loaded rats at $16 \mathrm{~h}$ after operation, and were assayed as described in Methods. Mean $\pm \mathrm{SE} ; n=6$ for both groups.

$* P<0.05$ vs. controls.

acid-loaded rats is associated with increased taurocholate transport maximum $(8,9)$.

Entirely unexpected was the observation in both of these models of increased bile acid flux through secreting parenchyma that bile acid-independent canalicular flow also was increased. The mechanism for this effect was not apparent. However, accumulating evidence suggests that this component of bile flow may reflect canalicular membrane NaK-ATPase activity. Thus, it is inhibited by known inhibitors of the enzyme such as ouabain and ethacrynic acid (1). Moreover, in a variety of experimental circumstances, changes in bile acid-independent flow correlate with changes in the activity of NaK-ATPase. Examples include the decreases produced by estrogens (33) and by chlorpromazine and its metabolities (34-36) and the increases produced by thyroxine (4) and phenobarbital (5) administration. In seeming contradiction to this evidence, other studies in whole animals or perfused livers have shown that inhibitors of NaK-ATPase had little or no effect on bile secretion or even induced a choleresis $(37,38)$, while in other systems, increased liver plasma membrane NaK-ATPase activity was not associated with changes in bile flow (39). These apparent inconsistencies are considered further below, but at the present time the concept that canalicular NaK-ATPase is related to bile secretion must be regarded as tentative.

In the present studies, it was felt that the validity of that concept might be tested by an examination of canalicular NaK-ATPase activity under conditions in which bile acid-independent flow was shown to be modulated by increased bile acid flux. Enzyme activities were measured in liver plasma membrane preparations from controls, from the obstructed and nonobstructed lobes of selectively obstructed animals, and from bile acid-loaded animals. The present findings are consistent with a relationship between bile acid-independent flow and NaK-ATPase activity, in 
that both were increased under conditions in which bile acid flux was increased. However, the activities of other enzymes also were increased, suggesting that this may reflect a relatively nonspecific response of the canalicular membrane.

That this did not represent simply an immediate physical effect of bile acids is suggested by the finding that these changes were not evident in bile acid loading experiments conducted over only $16 \mathrm{~h}$, in which bile acid pool and secretion rate were also increased, albeit to a lesser degree than in the 48 -h experiments. This agrees with the findings of Nemchausky et al. who showed that taurocholate did not affect canalicular NaK-ATPase in rats after $18 \mathrm{~h}$ of parenteral administration at higher rates than employed in the present studies $(40,41)$. However, the observation by these investigators that dehydrocholate administration did enhance NaK-ATPase activity supports the concept, suggested also by our findings, that properties of the canalicular membrane may be affected by bile acids and other amphipathic substances. Similarly, Triton WR1339, a nonionic detergent, recently was shown to produce significant changes in the composition and physical properties of the canalicular membrane and to reverse estrogen-induced cholestasis in rats (42).

One property of the canalicular membrane which is known to affect NaK-ATPase activity is membrane lipid composition and fluidity (43-47). Preliminary studies suggest that under the present experimental conditions, increased bile acid flux is associated with an increase in canalicular membrane cholesterol, relative to both phospholipid and protein (unpublished). By itself, this change, which could decrease membrane fluidity, would not be expected to be associated with increased NaK-ATPase activity (47), suggesting that increased enzyme activity may result from increases in either the amount of enzyme protein or of canalicular membrane. In support of this possibility, the recent findings of Nemchausky et al., employing scanning electron microscopy, suggest that portions of the canalicular membrane may expand after bile acid loading (41). In other studies (48), morphometric analysis of the liver in selectively obstructed rats failed to demonstrate a significant change in the canalicular space in the bile-secreting lobes, but the surface area of the canalicular membrane itself was not measured. Clarification of the significance of these findings will require more detailed studies of the canalicular membrane, including lipid composition and fluidity, enzyme kinetics, and morphometric analysis of membrane ultrastructure.

It must be recognized that preparations of canaliculi-enriched liver plasma membranes contain plasma membranes from regions of the hepatocyte other than the canaliculus, and other membranous cell components as well. Although newer techniques may permit greater purity $(49,50)$, current limitations in methodology must be considered when interpreting experimental findings. In particular, the distribution and possible heterogeneity of NaK-ATPase around the perimeter of the cell is uncertain. In intestinal and renal epithelium, for example, it has been shown that NaK-ATPase is relatively concentrated in that portion of the plasma membrane which faces the direction of net $\mathrm{Na}^{+}$flux (51-53). Similarly, in liver plasma membrane subfractions, Toda et al. (49) showed that NaK-ATPase specific activity is greater in a canalicular membrane fraction than in a sinusoidal membrane fraction. However, it remains a possibility that total liver plasma membrane NaK-ATPase is principally accounted for by enzyme on the sinusoidal aspect of the cell. Also, it is possible that the enzymes at the two poles of the cell respond differently (qualitatively or quantitatively) to physiological or pharmacological influences.

In view of these considerations, a number of findings in the literature which at the present time seem inconsistent may eventually be reconciled as improved methods permit study of these areas of current uncertainty. For example, in the intact animal or perfused liver, NaK-ATPase at the sinusoidal surface might be more susceptible than canalicular ATPase to inhibition by ouabain (e.g., bile acid micelles in the canaliculus could interfere with the binding of ouabain to canalicular NaK-ATPase). Under these conditions, an ouabain-induced increase in intracellular $\mathrm{Na}^{+}$could promote greater transport of $\mathrm{Na}^{+}$into the canaliculus and thereby account for increased bile flow (38). Similarly, glucocorticoids could preferentially enhance NaK-ATPase activity at the sinusoidal surface (reflected in liver plasma membrane preparations) without affecting bile flow (39). Conversely, a selective increase in the activity of NaK-ATPase in the canalicular portion of the plasma membrane might not be detectable as a change in total hepatocyte NaK-ATPase, as measured in the cell homogenate. Finally, phenobarbital, which affects a wide variety of cell membranes, might increase enzyme activity in sinusoidal and canalicular membranes, and homogenate as well as bile flow (5). It is clear that until sinusoidal and canalicular plasma membranes can be separated reliably and respective NaK-ATPase activities compared under a variety of conditions, all experimental data in this important area will have to be interpreted with appropriate caution.

In conclusion, our studies show that bile acid"independent" secretion is modulated by bile acid flux through the liver cell. Also, by demonstrating parallel changes in canalicular membrane NaK-ATPase activity and bile acid-independent flow, the findings are consistent with the concept that they may be functionally related. Elucidation of the mechanism by which bile acids effect these and previously reported adaptive 
changes in bile secretion will be of importance in the further understanding of this complex process.

\section{ACKNOWLEDGMENTS}

We express our appreciation to Wei-Lan Ma for expert technical assistance, to Anne Payne and Andrea Presberg for skilled secretarial assistance, and to Dr. F. Ismail-Beigi for his constructive review of the manuscript.

These studies were supported in part by research grant AM-13328, by Special Research Fellowship AM-57149 and Clinical Investigator Award AM-00132 (R. A.), and by Research Career Development Award AM-36586 (R. O), all from the National Institutes of Health, and by a Fellowship Award from the Deutsche Forschungsgemeinschaft (F-J. W.).

\section{REFERENCES}

1. Wheeler, H. O. 1975. Secretion in bile. In Diseases of the Liver. L. Schiff, editor. J. B. Lippincott Company, Philadelphia. 87-110.

2. Wheeler, H. O., E. D. Ross, and S. Bradley. 1968. Canalicular bile production in dogs. Am. J. Physiol. 214: 866-874.

3. Erlinger, S., and D. Dhumeaux. 1974. Mechanisms and control of secretion of bile water and electrolytes. Gastroenterology. 66: 281-304.

4. Layden, T. J., and J. L. Boyer. 1976. The effect of thyroid hormone on bile salt independent flow and $\mathrm{Na}^{+}, \mathrm{K}^{+}$ ATPase activity in liver plasma membranes enriched in bile canaliculi. J. Clin. Invest. 57: 1009-1018.

5. Simon, F. R., E. Sutherland, and L. Accatino. 1977. Stimulation of hepatic sodium and potassium-activated adenosine triphosphatase activity by phenobarbital. Its possible role in regulation of bile flow. J. Clin. Invest. 59: 849-861.

6. Cooper, A. D., A. L. Jones, R. E. Koldinger, and R. K. Ockner. 1974. Selective biliary obstruction: a model for the study of lipid metabolism in cholestasis. Gastroenterology. 66: 574-585.

7. Adler, R. D., and R. K. Ockner. 1974. Bile acid metabolism in selective biliarv obstruction. Gastroenterology. 67: A-1. (Abstr.)

8. Adler, R. D., F-J. Wannagat, and R. K. Ockner. 1975. Adaptation of bile secretion in selective biliary obstruction. Gastroenterology. 69: A-1. (Abstr.)

9. Adler, R. D., F-J. Wannagat, and R. K. Ockner. 1977. Bile secretion in selective biliary obstruction: adaptation of taurocholate transport maximum to increased secretory load in the rat. Gastroenterology. 73: 129-136.

10. Wannagat, F-J., R. D. Adler, and R. K. Ockner. 1976. Enhanced bile salt independent flow associated with augmented bile acid flux: studies of membrane ATPases. Gastroenterology. 70: A-138. (Abstr.)

11. Bollman, J. L. 1948. A cage which limits the activity of rats. J. Lab. Clin. Med. 33: 1348.

12. Strasberg, S. M., K. A. Siminovitch, and R. G. Ilson. 1974. Bile production in fasted and fed primates. Ann. Surg. 180: $356-363$.

13. Häcki, W., and G. Paumgartner. 1973. Determination of the biliary dead space using ${ }^{14} \mathrm{C}$-taurocholate as a marker. Experientia (Basel). 29: 1091-1093.

14. Boyer, J. L., and G. Klatskin. 1970. Canalicular bile flow and bile secretory pressure. Evidence for a non-bile salt dependent fraction in the isolated perfused rat liver. Gastroenterology. 59: 853-859.

15. Song, C. S., W. Rubin, A. B. Rifkind, and A. Kappas. 1969.
Plasma membranes of the rat liver. Isolation and enzymatic characterization of a fraction rich in bile canaliculi. $J$. Cell Biol. 4: 124-132.

16. Boyer, J. L., and D. Reno. 1975. Properties of $\left(\mathrm{Na}^{+}+\mathrm{K}^{+}\right)$activated ATPase in rat liver plasma membranes enriched with canaliculi. Biochim. Biophys. Acta. 40: 59-72.

17. Lowry, O. H., N. J. Rosebrough, S. L. Farr, and R. J. Randall. 1951. Protein measurement with the Folin phenol reagent. J. Biol. Chem. 193: 265-275.

18. Folch, J., M. Lees, and G. H. Sloane Stanley. 1957. A simple method for the isolation and purification of total lipids from animal tissues. J. Biol. Chem. 226: 497-509.

19. Bartlett, G. R. 1959. Phosphorus assay in column chromatography. J. Biol. Chem. 234: 466-468.

20. Marinetti, G. V. 1962. Chromatographic separation, identification and analysis of phosphatides.J. Lipid Res. 3: $1-24$.

21. Talalay, P. 1960. Enzymatic analysis of steroid hormones Methods Biochem. Anal. 8: 119-143.

22. Admirand, W. H., and D. M. Small. 1968. The physicochemical basis of cholesterol gallstone formation in man. J. Clin. Invest. 47: 1043-1052.

23. Ismail-Beigi, F., and I. S. Edelman. 1971. The mechanism of the calorigenic action of throid hormone. Stimulation of the $\mathrm{Na}^{+}+\mathrm{K}^{+}$-activated adenosine triphosphatase activity. J. Gen. Physiol. 57: 710-722.

24. Emmelot, P., and C. J. Bos. 1966. Studies in plasma membranes. III. $\mathrm{Mg}^{++}$-ATPase, $\left(\mathrm{Na}^{+}-\mathrm{K}^{+}-\mathrm{Mg}^{++}\right)$-ATPase and 5 -nucleotidase activity of plasma membranes isolated from rat liver. Biochim. Biophys. Acta. 120: 369-382.

25. Bakkeren, J. A. J. M., and S. L. Bonting. 1968. Studies on $\left(\mathrm{Na}^{+}-\mathrm{K}^{+}\right)$-activated ATPase. XX. Properties of $\left(\mathrm{Na}^{+}\right.$ $-\mathrm{K}^{+}$)-activated ATPase in rat liver. Biochim. Biophys. Acta. 150: 460-466.

26. Fiske, C: H., and Y. Subbarow. 1925. The colorimetric determination of phosphorus. J. Biol. Chem. 66: 375-40).

27. Emmelot, P., C. J. Bos, E. L. Benedetti, and P. H. Rümke. 1964. Studies in plasma membranes. I. Chemical composition and enzyme content of plasma membranes isolated from rat liver. Biochim. Biophys. Acta. 90: 126-145.

28. Tisdale, H. D. 1967. Preparation and properties of succinic-cytochrome C reductase (Complex II-III). Methods Enzymol. 10: 213-215.

29. Masters, M. S. S., C. H. Williams, Jr., and H. Kamin. 1967. The preparation and properties of microsomal TPNH cytochrome C reductase from pig liver. Methods Enzymol. 10: $565-573$.

30. Snedecor, G. W., and W. G. Cochran. 1967. Statistical Methods. Iowa State University Press, Ames, Iowa. 6th edition. 593 pp.

31. Goresky, C. 1975. The hepatic uptake process: its implications for bilirubin transport. In Jaundice. C. A. Goresky and M. M. Fisher, editors. Plenum Press, New York. 159-173.

32. Accatino, L., and F. Simon. 1976. Identification and characterization of a bile acid receptor in isolated liver surface membranes. J. Clin. Invest. 57: 496-508.

3.3. Simon, F. R., E. Sutherland, and L. Accatino. 1976. The effect of cholestasis produced by ethinyl estradiol on bile acid binding and (Na-K)ATPase activity in rat liver surface membranes. Clin. Res. 24: 105A. (Abstr.)

34. Ros, E. D., D. M. Small, and M. C. Carey. 1975. The effects of chlorpromazine hydrochloride on bile formation and biliary lipid secretion in the primate. Gastroenterolog!y. 68: A-118. (Abstr.)

35. Boyer, J. L., and M. Root. 1976. Chlorpromazine metabolites-inhibitors of $\mathrm{Na}^{+}, \mathrm{K}^{+}$-ATPase in liver 
plasma membranes enriched in bile canaliculi. Clin. Res. 24: 281A (Abstr.)

36. Samuels, A. M., and M. C. Carey. 1976. Effects of chlorpromazine (CPZ) and its metabolites on $\mathrm{Na}^{+}$, $\mathrm{K}^{+}$-ATPase activity of canalicular enriched liver plasma membranes. Gastroenterology. 70: A-75. (Abstr.)

37. Shaw, H., I. Caple, and T. Heath. 1972. Effect of ethacrynic acid on bile formation in sheep, dogs, rats, guinea pigs and rabbits. J. Pharmacol. Exp. Ther. 182: 27-33.

38. Graf, J., and M. Peterlik. 1976. Ouabain-mediated sodium uptake and bile formation by isolated perfused rat liver. Am. J. Physiol. 230: 876-885.

39. Leffell, D., J. Dobbins, C. A. Riely, and H. J. Binder. Evidence against stimulation of bile flow by Na-K ATPase. 1977. Clin. Res. 25: 314A. (Abstr.)

40. Nemchausky, B. A., J. L. Boyer, T. J. Layden, and J. Schwarz. 1976. In vivo effects of bile acids on canalicular membrane enzymes, lipid composition and 3-dimensional structure. Gastroenterology. 70: A-131. (Abstr.)

41. Nemchausky, B. A., T. J. Layden, and J. L. Boyer. 1977. Effects of chronic choleretic infusions of bile acids on the membrane of the bile canaliculus. A biochemical and morphological study. Lab. Invest. 36: 259-267.

42. Simon, F. R., M. Sinensky, F. Kern, and R. A. Davis. 1977. Reversal of ethinyl estradiol induced cholestasis: correlative changes in liver surface membrane structure and function. Clin. Res. 25: 318A. (Abstr.)

43. Kimelberg, H. K., and D. Papahadjopoulos. 1972. Phospholipid requirements for $\left(\mathrm{Na}^{+}+\mathrm{K}^{+}\right)$-ATPase activity: head group specificity and fatty acid fluidity. Biochim. Biophys. Acta. 282: 277-292.

44. Barnett, R. E., and J. Palazzotto. 1974. Mechanisms of the effects of lipid phase transitions on the $\mathrm{Na}^{+}, \mathrm{K}^{+}$-ATPase, and the role of protein conformational changes. Ann. N.Y. Acad. Sci. 242: 69-76.

45. Solomonson, L. P., V. A. Liepkalns, and A. A. Spector.
1976. Changes in $\left(\mathrm{Na}^{+}+\mathrm{K}^{+}\right)$-ATPase activity of Ehrlich ascites tumor cells produced by alteration of membrane fatty acid composition. Biochemistry. 15: 892-897.

46. Hilden, S., and L. Hokin. 1976. Coupled $\mathrm{Na}^{+}+\mathrm{K}^{+}$ transport in vesicles containing a purified (NaK)-ATPase and only phosphatidyl choline. Biochem. Biophys. Res. Commun. 69: 521-527.

47. Kimelburg, H. K. 1975. Alterations in phospholipiddependent $\left(\mathrm{Na}^{+}+\mathrm{K}^{+}\right)$-ATPase activity due to lipid fluidity effects of cholesterol and $\mathrm{Mg}^{++}$. Biochem. Biophys. Acta. 413: 143-156.

48. Jones, A. L., D. S. Schmucker, R. D. Adler, R. K. Ockner, and J. S. Mooney. 1976. A quantitative analysis of hepatic ultrastructure in rats after selective biliary obstruction. In The Liver, Quantitative Aspects of Structure and Function. R. Preisig, J. Bircher, and G. Paumgartner, editors. Editio Cantor, Aulendorf. 36-51.

49. Toda, G., H. Oka, T. Oda, and Y. Ikeda. 1975. Subfractionation of rat liver plasma membrane. Uneven distribution of plasma membrane-bound enzymes on the liver cell surface. Biochim. Biophys. Acta. 413: 52-64.

50. Fisher, M. M., D. L. Bloxam, M. Oda, M. J. Phillips, and I. M. Yousef. 1975. Characterization of rat liver cell plasma membranes. Proc. Soc. Exp. Biol. Med. 150: 177-184.

51. Murer, H., U. Hopfer, E. Kinne-Saffran, and R. Kinne. 1974. Glucose transport in isolated brush border and lateral basal plasma-membrane vesicles from intestinal epithelial cells. Biochim. Biophys. Acta. 345: 170-179.

52. Kyte, J. 1976. Immunoferritin determination of the distribution of $\left(\mathrm{Na}^{+}+\mathrm{K}^{+}\right)$-ATPase over the plasma membranes of renal convoluted tubules. I. Distal segment. J. Cell Biol. 68: 287-303.

53. Kyte, J. 1976. Immunoferritin determination of the distribution of $\left(\mathrm{Na}^{+}+\mathrm{K}^{+}\right)$-ATPase over the plasma membranes of renal convoluted tubules. II. Proximal segment. J. Cell Biol. 68: 304-318. 